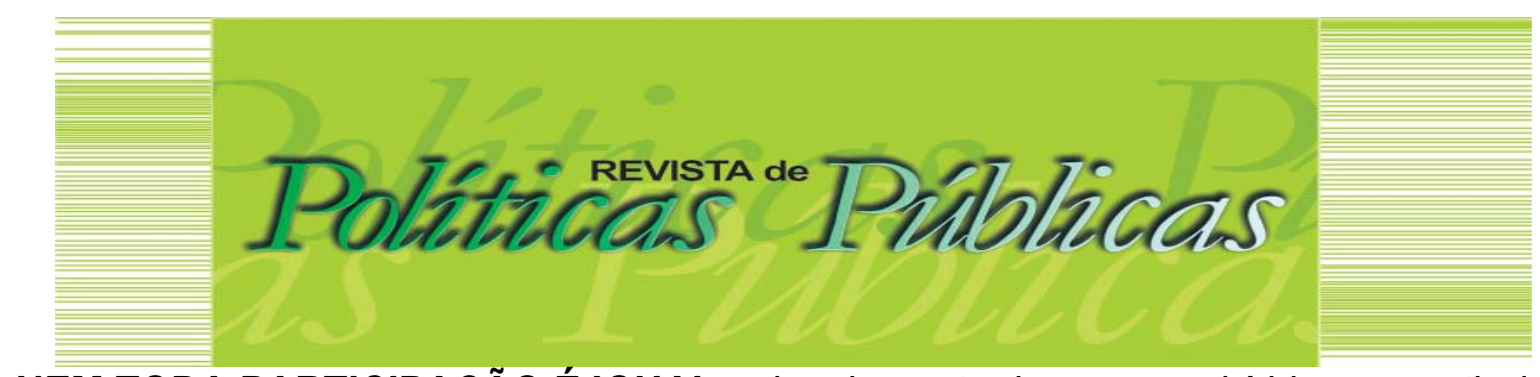

\title{
NEM TODA PARTICIPAÇÃO É IGUAL: planejamento de recursos hídricos a partir dos níveis de empoderamento ${ }^{1}$
}

\author{
Desirée Cipriano Rabelo² \\ Andréa Barborsa Alves ${ }^{3}$
}

\section{Resumo}

Para avaliar a qualidade democrática dos processos participativos de planejamento de recursos hídricos (PRHs), especialmente "como se participa", o artigo buscou as referências clássicas dos níveis de participação, em particular os níveis adotados pelas organizações multilaterais: Informação, Consulta e Envolvimento Ativo. Com base nesses níveis, classificou as informações sobre métodos/estratégias participativas dos relatórios oficiais dos processos de elaboração de PRHs das bacias dos Doce, São Francisco, Velhas, Santa Maria da Vitória e Jucu e Piracicaba, Capivari e Jundiaí. Parte da premissa que nem toda participação é igual e há formas crescentes de partilha de poder na relação governo-cidadão. A análise aponta a banalização do termo "participativo" e a necessidade da transparência dos objetivos e abrangência da participação pública nos PRHs e processos semelhantes.

Palavras chaves: Participação pública. Recursos hídricos. Planejamento. Plano de bacia.

NOT ALL PARTICIPATION IS EQUAL: river basin planning from the levels of empowerment

\section{Abstract}

In order to evaluate the democratic quality of participation in water resources planning processes (PRHs), especially in "the methods of participation", the research takes the classic references of participation levels, particularly, the levels assumed by the multilateral organizations: Information, Consultation and Active Involvement. This was used to classify the official reports about participation methods/strategies by of five basin planning of: Doce, São Francisco, Santa Maria da Vitória and Jucu and Piracicaba, Capivari and Jundiai rivers. The premise is that not all participation is equal and that there are increasing forms of power sharing in the government-citizen relationship. The analysis shows the trivialization of the term "participation" and the need for transparency of the objectives and scope of public participation in the PRHs and similar processes.

Keywords: Public Participation. Water resources. Planification. River Basin Plans.

Artigo recebido em: 04/12/2019 Aprovado em: 23/04/2020 DOI: http://dx.doi.org/10.18764/2178-2865.v24n1p442-467.

\footnotetext{
1 Este artigo apresenta resultados parciais da pesquisa Aperfeiçoamento de processos participativos de planejamento de recursos hídricos no âmbito de comitê de bacia (CNPq 462399/2014-1) desenvolvida no Laboratório de Gestão de Recursos Hídricos e Desenvolvimento Regional Universidade Federal do Espírito Santo.

2 Bacharel em Comunicação Social. Doutora em Comunicação social (UMESP) e Pós- Doutorado em Sociologia (UAB). Atualmente participa do LabGest (Laboratório de Gestão de Recursos Hídricos e Desenvolvimento Regional) da Universidade Federal do Espírito Santo e é professora no Mestrado Profissional em Rede Nacional em Gestão e Regulação de Recursos Hídricos (PROFÁGUA. Endereço da universidade de vínculo: Av. Fernando Ferrari, 514 - Goiabeiras, Vitória ES, 29075-910. E-mail: desiree_ufes@yahoo.com.br

${ }^{3}$ Assistente Social. Mestre pelo Programa de Pós-Graduação em Política Social da Universidade Federal do Espírito Santo (UFES), especialista em Gestão de Política de Saúde Informadas por Evidência (Hospital Sírio Libanês) e Regulação, Controle, Avaliação e Auditoria em Saúde (Faculdades Integradas Espirito Santense - FAESA). Assistente Social da Prefeitura Municipal de Vitória/ES, atuando como Gerente de Regulação, Controle e Avaliação . Endereço do órgão de vínculo: Av. Mal. Mascarenhas de Moraes, 1185 - Forte São João, Vitória - ES, 29017-010. E-mail: andrea.eades@gmail.com
} 


\section{INTRODUÇÃO}

A partir da última década do século $\mathrm{XX}$, os organismos internacionais passaram a recomendar fortemente a participação dos usuários no planejamento e execução das políticas, programas e ações de recursos hídricos (CCE, 2000, 2003; CIAMA, 1992; CNUMAD, 1992). No Brasil, a orientação foi assumida na Lei 9433/1997 - Política Nacional de Recursos Hídricos (PNRH) que prevê, entre seus instrumentos de gestão, os planos de recursos hídricos ou de bacia hidrográfica (PRHs). Nos territórios onde há disputas pelo uso da água, os planos "estabelecem, de forma organizada, as soluções negociadas nos respectivos comitês de bacia, com objetivo de minimizar os atuais e evitar os futuros conflitos" (ANA, 2013, p. 12). Por isso, mais importante do que um plano que contemple todas as questões relacionadas aos recursos hídricos é que ele resulte de um "pacto construído entre os atores envolvidos" (ANA, 2013. p. 21). Segundo determina a Resolução do Conselho Nacional de Recursos Hídricos (CNRH) No145/2012, a sociedade deve participar em todas as etapas do planejamento. Mas, cabe aos Comitês de Bacia Hidrográfica (CBHs) a decisão por sua elaboração; a promoção da articulação dos arranjos e recursos necessários; o acompanhamento dos trabalhos e a aprovação do plano final.

Em 2016, os 12 PRHs de bacias interestaduais elaborados, em processo de revisão ou de elaboração, cobriam uma área correspondente a $54 \%$ do território nacional. Já em relação às bacias estaduais, 164 delas já tinha o PRH elaborado, a maioria deles aprovada antes de 2010 (ANA, 2017). Ou seja, 20 anos após a aprovação da Lei 9.433, o planejamento de recursos hídricos no Brasil, com participação da sociedade, é uma prática institucionalizada. Não se trata de um fenômeno isolado: de forma crescente, desde a Constituição de 1988, as Instituições Participativas (IPs)1- como conselhos gestores e conferências públicas, dentre outras - integram a gestão pública em todos os níveis. E tornaram-se um tema central entre os pesquisadores das Ciências Sociais, com o desenvolvimento de um arcabouço teórico-analítico significativo para compreensão tanto do seu funcionamento quanto de seus resultados efetivos (AVRITZER, 2011). Um amplo conjunto de ferramentas e subsídios contemplam esses aspectos, reconhecendo as múltiplas questões que incidem sobre as IPs. $O$ desafio é avaliar se e como elas produzem impactos sobre a atuação de governos (IPEA, 2010; PIRES et al., 2011). Nesse sentido dois pontos são considerados chaves:

i) a qualidade dos processos participativos é elemento fundamental para entendermos os efeitos e impactos produzidos por IPs; e ii) é necessário utilizar múltiplas perspectivas, enfoques, estratégias e técnicas de análise (desde estudos em profundidade sobre um único caso a estudos comparativos e de grandes amostras) para avaliar as dimensões de atuação e os variados resultados produzidos por IPs (PIRES et al., 2011, p. 361). 
Nessa mesma linha, Tatabiga (2003, p.15) aponta que a identificação e a discussão dos condicionantes da efetividade e da qualidade dos resultados da participação nos processos de gestão têm animado a produção e os debates no âmbito da teoria democrática contemporânea. Alguns desses condicionantes são apontados por Escorel (2015, p. 2061):

Conferências (e conselhos) só podem suprir os déficits democráticos do modo tradicional de
formulação das políticas se apresentarem certas características: diversidade de composição,
acompanhada de simetria de poder interno e de representatividade dos participantes; pro-
cessos democráticos de deliberação e de tomada de decisão; transparência e mecanismos
de responsabilização pelas decisões e suas consequências; e formas de pressionar o poder
constituído tanto para que este leve em conta as deliberações tomadas nas instâncias parti-
cipativas quanto para que as instâncias possam efetivamente acompanhar e monitorar a
formulação e implementação das políticas governamentais.

Todas essas questões também incidem sobre os CBHs e os conselhos que integram o Sistema de Gerenciamento de Recursos Hídricos (SINGREH) e, igualmente, têm merecido atenção dos pesquisadores ${ }^{2}$. Contudo, mais escassas são as avaliações relativas à participação no planejamento de recursos hídricos - um dos instrumentos de gestão previstos pela PNRH. Provavelmente porque se trata de um mecanismo de planejamento mais recente, não permanente (ao menos 0 ato de planejar), cujas complexidades e especificidades dificultam análises e especialmente estudos comparativos. Em termos nacionais, a ANA tem realizado levantamentos que oferecem um panorama geral e identificam problemas recorrentes. Dentre eles está o da baixa efetividade na implementação das ações definidas pelos PRHs. Segundo a entidade, "[...] há pouco rebatimento dos planos na programação e orçamento dos órgãos gestores estaduais de recursos hídricos" (ANA, 2017, p. 116).

Organizações externas concordam com essa avaliação. Por exemplo, o estudo desenvolvido pela World Wildlife Fund Brasil (WWF) e a Fundação Getúlio Vargas (FGV) (LIMA, 2014) sinalizou a falta de monitoramento da efetividade dos planos de recursos hídricos no Brasil. Já a Organização para a Cooperação e o Desenvolvimento Econômico adverte que, em geral, os PRHs são "um exercício do tipo pensamento positivo [...] mal coordenados e de fraca efetividade na prática, devido à falta de capacidade tanto de implementação quanto de financiamento [...] não passam de tigres de papel ou promessas a serem cumpridas por outros" (OCDE, 2015, p. 20). Uma crítica aparentemente assumida no relatório Análise de Conjuntura 2016 em seu capítulo sobre o planejamento dos recursos hídricos (ANA, 2017).

Tratamos aqui de outro aspecto do planejamento de recursos hídricos: a participação da sociedade nas diferentes etapas da elaboração - conforme prevê a Resolução n 145/2012 do CNRH. Os dados e discussões desenvolvidos neste artigo constituem-se resultados parciais da pesquisa Aperfeiçoamento de processos participativos de planejamento de recursos hídricos no âmbito de comitê de bacia. Um dos produtos da investigação foi a construção da Matriz de análise da qualidade democrática 
de processos participativos de planejamento de recursos hídricos (QUADEPLARH). Reconhecendo que cada perspectiva avaliativa guarda potencialidades e fragilidades, a pesquisa partiu da proposta teórico-metodológica desenvolvida pelo Observatório Internacional de Democracia Participativa (OIDP, 2006). Segundo o OIDP, os múltiplos aspectos que incidem sobre a qualidade democrática dos processos participativos podem ser agrupados em cinco dimensões de análise: Coordenação do processo; Quem participa (Participantes); Sobre o que se participa; Como se participa (Método) e Resultados da participação - que se desdobram em vários critérios e seus respectivos indicadores de avaliação.

Considerando as diretrizes institucionais e legais da PNRH, as recomendações internacionais sobre gestão da água e a conjuntura sociopolítica e as especificidades brasileiras, a QUADEPLA$\mathrm{RH}$ tomou como referência as cinco dimensões mencionadas e propôs 10 grupos de critérios de análise que resultaram em 14 indicadores e 43 parâmetros/questões específicas sobre os processos de elaboração de PRHs. Neste artigo abordamos os resultados da análise da dimensão Como se participa ou Método de Participação. Interessa-nos, sobretudo, contribuir com o aperfeiçoamento dos resultados efetivos da participação, e não apenas melhorar a participação pela participação (IPEA, 2010; PIRES at al., 2011). Quer seja: a contribuição da participação social na melhoria das políticas públicas, em nosso caso os planos de bacia, superando os gaps comuns na gestão dos recursos hídricos (OCDE, 2015).

\subsection{Os processos em análise}

Para testagem da QUADEPLARH foram escolhidos cinco PRHs já elaborados: das bacias dos rios: Doce; Piracicaba, Capivari e Jundiaí (PCJ); Santa Maria e Jucu; São Francisco e Velhas. Este recorte foi feito com base nos seguintes critérios: temporalidade (a partir de 2010), dominialidades dos rios (estadual da União), empresas de consultoria (presumindo abordagens metodológicas distintas) e acessibilidade dos dados. Em relação à obtenção de dados, realizou-se uma pesquisa documental cujo material base foram planos aprovados, termos de referência (TRs), planos de trabalho, relatórios parciais e finais referentes aos cinco planejamentos selecionados. Para a coleta de dados também foram consultados os sítios dos comitês e da Agência Nacional de Águas. De maneira complementar, recorremos aos mecanismos de busca com as palavras chave: planos de bacia, participação pública, participação ativa, consulta pública, reuniões públicas. Os levantamentos na Internet foram realizados entre novembro de 2017 a janeiro de 2018. Apresentamos, em seguida, uma breve descrição das regiões hidrográficas destacadas e seus respectivos $\mathrm{CBHs}_{\text {e }}$ planos 3 . 
Quadro 1 - Descrição das bacias em estudo e da gestão dos RHs

\begin{tabular}{|c|c|c|c|}
\hline & Características gerais & Principais conflitos da bacia & Gestão dos RH \\
\hline $\begin{array}{l}\text { Bacia do } \\
\text { Rio Doce }\end{array}$ & $\begin{array}{l}\text { EXTENSÃO: Entre os estados } \\
\text { de Minas Gerais e Espírito Santo } \\
\text { com abrangência em } 229 \text { muni- } \\
\text { cípios. } \\
\text { POPULAÇÃO: } 3,5 \text { milhões habi- } \\
\text { tantes. } \\
\text { IDH: De médio a alto }\end{array}$ & $\begin{array}{l}\text { De origem socioambiental, em relação } \\
\text { às áreas protegidas, conflitos urbanos, } \\
\text { infraestrutura e atividades agroindustri- } \\
\text { ais, agrícolas/pecuária e florestal. }\end{array}$ & $\begin{array}{l}\text { CBH Doce instituído em } \\
2002 . \\
\text { Plano (PIRH) aprovado } \\
\text { em } 2010 \text { com alcance } \\
\text { até } 2030 .\end{array}$ \\
\hline $\begin{array}{l}\text { Bacia dos rios } \\
\text { Piracicaba, } \\
\text { Capivari e } \\
\text { Jundiaí }\end{array}$ & $\begin{array}{l}\text { EXTENSÃO: Entre os estados } \\
\text { de São Paulo e Minas Gerais, } \\
\text { com abrangência em } 76 \text { municí- } \\
\text { pios. } \\
\text { POPULAÇÃO: } 5 \text { milhões habi- } \\
\text { tantes } \\
\text { IDH: De alto a médio }\end{array}$ & $\begin{array}{l}\text { Graves problemas de disponibilidade de } \\
\text { água em função da expansão urbana, } \\
\text { agrícola e industrial. Ocupação desor- } \\
\text { denada do solo e problemas decorren- } \\
\text { tes da eliminação de poluentes na } \\
\text { atmosfera. }\end{array}$ & $\begin{array}{l}\text { CBH PCJ instituído em } \\
1993 . \\
\text { Plano aprovado em } \\
2010 \text { com alcance até } \\
\text { 2020. Em abril de } 2018 \\
\text { finalizou revisão. }\end{array}$ \\
\hline $\begin{array}{l}\text { Bacia dos rios } \\
\text { Sta Maria da } \\
\text { Vitoria e Jucu }\end{array}$ & $\begin{array}{l}\text { EXTENSÃO: Localizadas na } \\
\text { região Centro-Sul do Estado do } \\
\text { Espírito Santo. Juntas abrangem } \\
10 \text { municípios. } \\
\text { POPULAÇÃO: } 1,8 \text { milhões habi- } \\
\text { tantes } \\
\text { IDH: Alto nas duas bacias }\end{array}$ & $\begin{array}{l}\text { Poluição do rio e afluentes pelo lança- } \\
\text { mento de esgotos domésticos e efluen- } \\
\text { tes industriais. Mau uso do solo e da } \\
\text { água que gera a escassez e competição } \\
\text { entre os usuários, em especial as de- } \\
\text { mandas dos sistemas de irrigação } \\
\text { agrícola, abastecimento humano e } \\
\text { manutenção das vazões mínimas e } \\
\text { ecológicas do rio e afluentes. }\end{array}$ & $\begin{array}{l}\text { CBH de Santa Maria da } \\
\text { Vitória e CBH do Rio } \\
\text { Jucu instituídos em } \\
2007 . \\
\text { Projeto Executivo para } \\
\text { Enquadramento dos } \\
\text { Corpos de Água em } \\
\text { Classes e Plano apro- } \\
\text { vado em } 2016 \text { com } \\
\text { alcance até } 2036\end{array}$ \\
\hline $\begin{array}{l}\text { Bacia do rio } \\
\text { São } \\
\text { Francisco }\end{array}$ & $\begin{array}{l}\text { EXTENSÃO: Abrangendo os } \\
\text { estados de Minas Gerais, Bahia, } \\
\text { Pernambuco, Alagoas, Sergipe, } \\
\text { Goiás e o Distrito Federal e } 507 \\
\text { municípios. } \\
\text { POPULAÇÃO: } 18 \text { milhões habi- } \\
\text { tantes } \\
\text { IDH: Contrastes entre as regi- } \\
\text { ões: alto IDH no Alto S. Francis- } \\
\text { co e baixo na região metropolita- } \\
\text { na de B. Horizonte. }\end{array}$ & $\begin{array}{l}\text { Envolve a agricultura irrigada, a geração } \\
\text { de energia (instalação de barragens e } \\
\text { operação de reservatórios), o uso da } \\
\text { água para o abastecimento humano, a } \\
\text { diluição de efluentes urbanos, industri- } \\
\text { ais e da mineração e a manutenção de } \\
\text { ecossistemas. }\end{array}$ & $\begin{array}{l}\text { CBH S. Francisco insti- } \\
\text { tuído em } 2001 . \\
\text { Plano (PIRH) aprovado } \\
\text { em } 2016 \text { com alcance } \\
\text { até } 2025 .\end{array}$ \\
\hline $\begin{array}{l}\text { Bacia do rio } \\
\text { das Velhas }\end{array}$ & $\begin{array}{l}\text { EXTENSÃO: Afluente da Bacia } \\
\text { do São Francisco com abran- } \\
\text { gência de } 51 \text { municípios. } \\
\text { POPULAÇÃO: } 4,4 \text { milhões habi- } \\
\text { tantes } \\
\text { IDH: Na faixa do médio desen- } \\
\text { volvimento humano. }\end{array}$ & $\begin{array}{l}\text { Escassez hídrica por redução da pluvio- } \\
\text { sidade, somada ao impacto ambiental, } \\
\text { esgotos industriais e domésticos não } \\
\text { tratados. Degradação ambiental por } \\
\text { atividades minerais e montantes de } \\
\text { recursos hídricos revertidos para abas- } \\
\text { tecimento da região metropolitana. }\end{array}$ & $\begin{array}{l}\text { CBH Velhas instituído } \\
\text { em } 1998 . \\
\text { Plano Diretor aprovado } \\
\text { em } 2004 \text {. Revisado e } \\
\text { atualizado em } 2015 .\end{array}$ \\
\hline
\end{tabular}

Fonte: Elaborado pelas autoras com base nos diagnósticos produzidos nos processos de planejamento e sítios dos CBHs

\section{AS MUITAS FORMAS DE PARTICIPAR}

Se a Resolução CNRH 145/2012 define o caráter participativo do PRH, as indicações nesse sentido são vagas e mesclam elementos de natureza distinta: "consultas públicas, encontros técni- 
cos, oficinas de trabalho, meios de comunicação, inclusive virtuais, [...] estratégias de Educação Ambiental, Comunicação e Mobilização Social". Ou seja, observa-se uma imprecisão em relação ao termo "participação", confundido ou reduzido a técnicas e canais de informação.

Na mesma linha, ao discutir a lógica da gestão territorial participativa e descentralizada da PNRH, Machado (2003, p. 130) reitera sobre as distintas interpretações do termo participação "já que se pode participar ou tomar parte em alguma coisa de formas diferentes, que podem variar da condição de simples espectador, mais ou menos marginal, a de protagonista de destaque". Tratando também da política de recursos hídricos, Santos e Saito $(2006$, p. 09) identificam a "mitificação da participação". Segundo os autores, trata-se de uma prática comum, especialmente em tempos de crise, na medida em que o conceito é "apropriado e deturpado pelo setor dominante da sociedade como forma de obter uma pretensa legitimidade social às suas decisões".

Analisados isoladamente ou em conjunto, os relatórios dos PRHs estudados são igualmente pouco precisos na denominação ou caracterização dos procedimentos ditos participativos durante a elaboração dos mesmos, o que compromete as análises da dinâmica desses planejamentos e dos seus resultados. Nesse sentido, fez-se obrigatório, mais que recuperar o significado do termo, clarificar a concepção de participação que norteará este estudo.

Participar vem do latim participare, participatio. Com base na etimologia da palavra, em seu clássico estudo sobre participação, Bordenave (1994) aponta que as três dimensões de significados do termo - fazer parte, tomar parte e ter parte - sugerem diferentes possibilidades e implicações. Segundo o autor, a avaliação da participação num grupo ou organização depende de duas questões fundamentais: Qual é o grau de controle dos membros sobre as decisões? Quão importantes são as decisões de que se pode participar? Das respostas a essas questões, resulta a sua conhecida proposta de escala dos graus ou níveis de participação:

Figura 1 - Níveis de participação

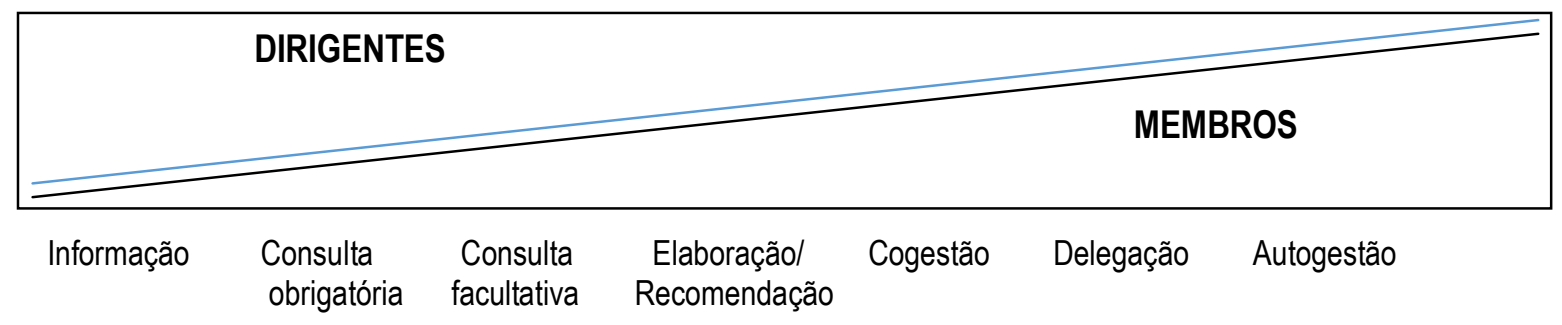

(Fonte: Bordenave, 1994)

Classificações similares foram desenvolvidas por outros autores, dentre eles Arnstein (2002) e Henriques (2013). Em comum, todos apontam que os diferentes níveis de participação são medidos a partir do grau de envolvimento ou empoderamento dos cidadãos em relação às questões em debate. $O$ último nível de participação é denominado Auto-gestão, Controle Cidadão ou Participação 
Institucional, conforme cada autor. Alguns autores assumem explicitamente que o objetivo é a partilha do poder (AVRITIZER, 2008; DAGNINO, 2014) que, em termos de gestão participativa, não se trata de uma abstração teórica, mas do reconhecimento que nem toda participação é igual. Nem toda participação culmina na partilha do poder ou no exercício da corresponsabilidade. A transparência sobre tal questão é, com certeza, fator de qualidade democrática nos processos participativos.

Buscando o sentido de participação em sua acepção política-institucional, com base na Constituição de 1988, em seu Artigo $1^{0} \S$ único, encontramos que "todo poder emana do povo, que o exerce por meio de representantes eleitos ou diretamente". Nesse aspecto, a elaboração de PRHs pode ser classificada como um dos tipos de IPs descritos por Avritzer (2008) - aqueles caracterizados pela "constituição de uma instituição na qual atores estatais e atores da sociedade civil participam simultaneamente" na deliberação sobre políticas públicas - neste caso, de recursos hídricos 4 .

Diante da imprecisão de denominação e caracterização dos procedimentos de participação observada nos relatórios dos PRHs, a análise dos espaços, instrumentos, técnicas e métodos, ditos participativos, tomou como referência os níveis ou graus de envolvimento/empoderamento que possibilitavam. Nesse sentido, as propostas decorrentes da Directiva Quadro da Água (DQA) da Comunidade Europeia (CCE, 2000; CCE, 2003) destacam-se como uma referência no debate sobre participação pública no planejamento e gestão dos recursos hídricos. A assunção de que o objetivo último da participação pública é a "partilha do poder", guiará a análise da qualidade democrática no planejamento dos recursos hídricos.

Segundo a DQA, a participação pública estimula a consciência sobre questões ambientais e aumenta a aceitação e o compromisso em relação aos planos aprovados, na medida em que possibilita que os cidadãos discutam e influenciem a tomada de decisões sobre tais planos (CCE, 2003). Abrange três níveis crescentes de envolvimento: informação pública - sobre o plano, desde as primeiras etapas, e sobre os procedimentos de decisão; consulta pública - período oficial de apresentação de observações por parte de interessados e público em geral; e envolvimento ou participação ativa - das pessoas e entidades interessadas ou afetadas e público em geral nos processos de decisão (CCE, 2000). Na próxima seção apresentamos as características e fundamentos teóricos e políticos de cada um dos níveis de participação pública, relacionando-os com os processos de elaboração PRH analisados.

3 PARTICIPAÇÃO NA ELABORAÇÃO DE PRHS : análise a partir dos níveis de envolvimento ou empoderamento 


\subsection{Informação}

A indicação da DQA que a Informação é o primeiro degrau ou etapa do processo de participação pública é fundamentada em vários autores, dentre eles Bordenave (1994) e Arnstein (2002). A DQA estabeleceu várias diretrizes para garantir o acesso e suprimento de informações especialmente na elaboração, revisão e atualização dos planos de gestão de bacia hidrográfica. Dentre elas a de que os Estados-Membros devem publicar e facultar ao público o calendário e o programa de trabalhos, inclusive com a lista das consultas a serem feitas, uma síntese das questões significativas relativas à gestão da água detectadas na bacia, o plano de gestão e os programas/projetos a ele relacionados (CCE, 2000, p. 14). Nesse sentido, é possível distinguir duas abordagens ou perspectivas relacionadas à Informação que, embora com interfaces, implicam objetivos e procedimentos distintos. A primeira perspectiva refere-se à Informação para a Mobilização, resultando em sensibilização, divulgação e orientação para a participação; já a segunda perspectiva versa sobre a Informação para a tomada de decisão.

Partindo da premissa de que "toda mobilização é um ato de comunicação" (TORO; WERNECK, 2004), assumimos o conceito dos três níveis de comunicação na mobilização (massa, macro e micro), com seus instrumentos/espaços, alcances e objetivos específicos. Em resumo, a comunicação aqui é compreendida como um processo que - com ou sem instrumentos de intermediação - possibilita a difusão de ideias, estimula sentidos e vontades, compartilha ações e resultados e, na mobilização, possibilita a construção do projeto coletivo (RABELO, 2003; TORO; WERNECK 2004). A comunicação de massa, além de reforçar a legitimidade do planejamento, o interesse na participação, a construção de acordos, etc., intensifica os resultados da comunicação nos níveis macro e micro. No Brasil, embora a abrangência da participação da sociedade na elaboração do plano de bacia seja uma decisão da coordenação, a ANA (2013, p. 23) sugere "um amplo processo de divulgação para que toda a população possa tomar conhecimento e acompanhar o que está sendo feito". Nos processos em estudo, essa questão foi tratada nos denominados planos de comunicação ou de mobilização social.

E aqui chamamos a atenção para a dissociação entre mobilização e comunicação, via de regra tratadas separadamente nos planos examinados, não considerando suas sinergias (RABELO, 2003; TORO; WERNECK, 2004). Observa-se a tendência de reduzir a comunicação à mídia massiva, 0 que explica o esforço comum em identificar e centrar esforços na chamada grande mídia, na produção/envio de relises (ou publicidade paga) com foco especialmente nos eventos públicos. Ainda assim, segundo os relatórios, de maneira geral a repercussão ou interesse dos meios massivos no planejamento de recursos hídricos foi insatisfatório. Entre as razões para esse aparente desinteresse pode 
estar a falta de uma visão/ação estratégica da comunicação de massa, inclusive da contratação de profissionais habilitados. Eventos burocráticos, como "reuniões" não atraem interesse midiático, ao contrário de temas como conflitos pelos usos da água ou riscos de desabastecimento na região, que poderiam ser usados como "gancho" (no sentido jornalístico do termo). De interesse do público e da mídia, a cobertura desses temas daria maior visibilidade e sentido ao planejamento de recursos hídri$\cos$ (e, logo, aos eventos relacionados). Processos semelhantes com bons resultados em termos de otimizar a comunicação numa perspectiva relacional - independente dos diferentes meios e espaços (MAFRA, 2006, MEDINA, 1998; RABELO, 2003) confirmam que há, sim, estratégias nesse sentido.

Mesmo considerando que os municípios de pequeno porte (cerca de 20.000 habitantes) fossem a maioria nas bacias pesquisadas - ou seja, pouca ou nenhuma mídia de grande porte e acesso limitado da população à Internet - em geral os planos de comunicação não deram prioridade às mídias locais, como carros ou bicicletas de som, rádios-poste, rádios ou tevês comunitárias, jornais de bairro, etc. Em tese, nesses municípios, onde também eram realizadas reuniões e/ou se localizavam algumas das organizações participantes do planejamento, são muito maiores as possibilidades de acesso às mídias locais, o que facilita não a divulgação dos eventos e o debate com foco nas questões hídricas locais e o envolvimento de novos atores.

Nos níveis de comunicação macro e micro, foi possível identificar nos Planos de trabalho (mas não nos de comunicação) o reconhecimento da diversidade dos atores e interesses com a construção de estratégias para além dos grandes eventos públicos. De fato, quatro dos cinco planos estudados promoveram ações destinadas a diferentes seguimentos estratégicos, buscando adesão ou discussão de temas de seu interesse ${ }^{5}$. Na bacia do São Francisco, por exemplo, foram realizadas 21 oficinas visando fortalecer os diagnósticos técnico-institucionais de cada região fisiográfica da bacia em relação aos seus principais segmentos: hidroeletricidade, navegação, pesca, turismo e lazer, indústria e agricultura, saneamento, povos indígenas e comunidades tradicionais. Realizadas antes das reuniões públicas de cada etapa do planejamento, as oficinais tiveram uma resposta positiva: 710 participantes, (87\% a mais do que o previsto). Por suas características, esses encontros cumpriam dupla função: Informação e Consulta. Também o relatório final do PCJ (2007) descreve o esforço do Comitê PCJ, Câmaras Técnicas e demais envolvidos na elaboração do plano, de reunir-se com os diferentes segmentos de usuários e da sociedade em geral. Nesse sentido, foram realizados seminários, oficinas temáticas e reuniões setoriais, visando esclarecer, fornecer subsídios técnicos sobre a temática, além de estimular e incorporar as contribuições dos públicos.

De fato, ações de comunicação nos níveis macro e micro a comunicação potencializam a adesão e o compromisso dos atores estratégicos, agregam informações e favorecem a negociação nos conflitos em torno dos usos da água. Contudo, identificamos que, em termos de transparência, falta 
maior publicização sobre esse tipo de atividade/comunicação. De maneira geral, os planos de trabalho ou relatórios dão maior destaque aos eventos públicos, como se fossem o ponto alto da participação quando, por sua própria natureza, eles destinam-se mais às apresentações (informação), deliberações (consultas) quando não servem como espetáculos (por exemplo, cerimônias de abertura do planejamento ou de entrega do plano). Propositalmente ou não, os relatos sobre visitas às autoridades, reuniões e debates com grupos particulares, costumam merecer menor atenção em termos de divulgação. Trata-se de um equívoco, já que nos encontros menores e com públicos segmentados ocorrem decisões importantes que afetam todo o processo - e por isso devem ser publicizados.

Tratemos agora da informação para a tomada de decisão 6 . Os processos com maior qualidade democrática são aqueles nos quais os participantes recebem toda a informação necessária, podem deliberar em condições de igualdade e, finalmente, tomar uma decisão democrática (OIDP, 2006). A Agenda 21 Global dedica $040^{\circ}$ capítulo a esse tema, estabelecendo uma relação direta entre acesso à informação e desenvolvimento sustentável (CNUMAD, 1992). Outro marco internacional nessa matéria é a Convenção de Aarhus sobre o acesso à informação, participação do público no processo de tomada de decisão e acesso à justiça em matéria de ambiente (CEE, 1998). No Brasil, o controle social democrático das ações do Estado, garantido pela Constituição Federal de 1988 (CF/88), impôs a necessidade de sistemas de informação correspondentes. Alguns marcos são as leis de acesso à Informação Ambiental (BRASIL, 2003) e a Informação Pública (BRASIL 2011). Já a PNRH criou o Sistema de informações sobre Recursos Hídricos (SINRH) cujo objetivo é reunir, tratar e divulgar os dados e informações sobre a situação qualitativa e quantitativa sobre o tema.

$\mathrm{O}$ acesso ao SINRH é assegurado a toda a sociedade para subsidiar a tomada de decisões, inclusive no planejamento dos recursos hídricos (BRASIL, 1997, p. 25). Na prática, esse direito é compreendido ou se resume basicamente à tradução e divulgação das informações técnico-científicas para o público não especializado. Segue-se, assim, o disposto no artigo $6^{\circ}$ da Resolução $\mathrm{CNRH}$ N¹45/2012: os estudos elaborados no planejamento sejam "divulgados em linguagem clara, apropriada e acessível a todos, pela entidade responsável pela sua elaboração". Tanto os Planos de trabalho como os Termos de Referência analisados tinham recomendações nessa linha. Reforçava-se a importância das apresentações (com apoio audiovisual) feitas nos eventos públicos e da produção e distribuição de materiais/subsídios impressos e disponibilizados em sítios eletrônicos.

Ainda que positivo, esse tipo de tradução é questionável, na medida em que pode implicar na simplificação da realidade e dos dados em debate (EMPINOTTI; JACOBI; FRACALANZA, 2016). Outros autores identificam aqui um dos aspectos que concorrem com a mitificação da participação: a crença de que todos os grupos sociais (poder público, usuários, comunidades) num $\mathrm{CBH}$ participam e contribuem em igualdade de condições, por exemplo, em relação ao conhecimento técnico científico, 
eloquência na fala e poder de argumentação (SANTOS; SAITO, 2006). Se, historicamente, a gestão dos recursos hídricos esteve a cargo de especialistas (sobretudo das engenharias), amparados pela técnica, tais gestores ou servidores públicos tendem a assumir que sabem o que é melhor para os cidadãos e "não entendem que as ciências e as tecnologias não devem tutelar a democracia direta na gestão sustentável das águas, pois nenhum desenvolvimento sustentável poderá existir sem a participação ampliada das populações envolvidas" (MACHADO, 2006, p. 182).

Outro aspecto que pode agravar as assimetrias de conhecimento entre os participantes é o tempo - ou a falta dele. A questão é: quanto tempo é necessário para processar uma informação complexa (ainda que traduzida)? E para discutir com as bases, já que cada participante representa um seguimento? Ou apresentar dúvidas, interesses que não foram observados na informação apresentada? Tendo em conta a complexidade de um planejamento de recursos hídricos, é colossal o volume de dados e aspectos a serem analisados. Analisando processos de planejamento de recursos hídricos na Espanha, Espluga e Subirats (2008) observaram que as limitações de prazos abreviam as possibilidades de discussão dos grupos interessados, introduzindo uma dinâmica de urgência que se reflete nas convocatórias das reuniões - com os participantes recebendo a documentação para análise e debate na véspera ou no mesmo dia do encontro.

Por outro lado, é mais difícil manter a mobilização e engajamento dos atores e setores estratégicos em processos demasiadamente longos, especialmente quando se considera que as ações/eventos ocorrem em distintas partes do território da bacia. Também aqui se evidencia a necessidade de mais análises para facilitar definições nesse sentido para futuros processos de planejamento. Porém, segundo Espluga e Subirats (2008) prazos curtos reduzem as condições de uma participação frutífera. Inclusive no nível seguinte de participação, o das consultas, do qual trataremos a seguir.

\subsection{Consulta}

Nas últimas décadas, as consultas aos cidadãos, em geral, stakeholders, organizações estratégicas ou especialistas passaram a ser parte integrante dos planejamentos. Em alguns países, como Finlândia, Islândia, Noruega, Suécia, a consulta pública e a contribuição do cidadão são práticas estabelecidas há muito tempo (OCDE, 2002). No Brasil, o capítulo 14 da CF/88 prevê o exercício da soberania popular pelo exercício do voto direto e secreto e, ainda, por plebiscito, referendo e iniciativa popular. Já o inciso II, $\S 2^{\circ}$ do Artigo 58 prevê a realização de audiências públicas com a finalidade de promover um diálogo entre a sociedade civil e o Congresso Nacional, bem como Assembleias Legislativas e Câmara de Vereadores. Paulatinamente as políticas setoriais introduziram as audiências públicas em casos de processos decisórios de grande relevância. E com o advento das Novas Tecnologias 
da Informação e Comunicação (NTIC) há uma ampliação de estratégias de participação dos cidadãos na construção das políticas públicas. Em 2018, por exemplo, em um sítio eletrônico, o Governo Federal brasileiro convidava os cidadãos a fazer contribuições e oferecia a relação e links das consultas abertas nos portais dos órgãos federais (BRASIL, 2018).

Se o objetivo, alcance e delineamento das consultas públicas são bem estabelecidos nas modalidades previstas na CF/88, o mesmo não ocorre em relação aos processos no planejamento de desenvolvimento local. Na definição de Buarque (1999, p.65) a ação ou etapa metodológica das consultas constitui-se num conjunto de técnicas voltadas para "atores, instituições e especialistas, supondo um tratamento separado dos três tipos de consultados e suas lógicas". A saber: oficina de trabalho de atores sociais (workshop), oficina de trabalho institucional (workshop), Diagrama Institucional, Diagnóstico Rápido Participativo (DRP), entrevista estruturada ou semiestruturadas, caminhadas de reconhecimento e técnica Delfos.

$\mathrm{Na}$ interpretação da Organização para a Cooperação e o Desenvolvimento Econômico (OCDE, 2002), as consultas são um nível mais avançado de participação, na medida em que possibilitam uma relação "bidirecional limitada entre o governo e os cidadãos". Na chamada consulta ativa, o governo define que pontos de vista serão buscados. Entre as ferramentas de consultas do tipo não permanentes, a OCDE (2002 p. 66-71) indica: processos abertos de perguntar, ouvir e prestar contas sobre temas determinados, com prazo e canais de respostas definidos; discussão com grupos representativos ou específicos, com entrevistas individuais e sessões plenárias para recolher seus pontos de vista e reações; pesquisas de opinião pública; inclusão de cidadãos individuais (peritos ou representantes de organizações) em órgãos consultivos; workshops, seminários, conferências; audiências públicas e plebiscitos.

A OCDE orienta que os Estados membros promovam uma ampla divulgação prévia sobre data, local e objeto da consulta - facilitando também as informações referentes ao tema tratado. Os procedimentos definidos para a consulta, por exemplo, em relação à seleção dos participantes a serem consultados, devem ser publicizados e respeitados. Se a seleção não for representativa e o critério usado for a proximidade com o poder político ou econômico, os resultados serão sem valor e provocarão a falta de confiança no governo. Também deve ser dada ampla divulgação às contribuições recebidas, além de garantido o seu uso. 0 não atendimento desses critérios, alerta a OCDE, compromete não apenas o resultado da consulta pública, mas as relações entre governo-cidadão. Em última instância, a efetividade das propostas aprovadas.

A DQA corrobora que a consulta é uma forma mais intensiva de participação pública e visa aprender com comentários, percepções, experiências e ideias de stakeholders. E que ele só é possível durante a preparação e/ou após a conclusão de planos preliminares e outros documentos (CCE 
2003). Em termos práticos, a DQA orienta que os comentários públicos devem ser recolhidos por escrito, em formulários, por e-mail ou cartas. Sugere, ainda, que formas consultas orais ou ativas também devem ser consideradas, como entrevistas, workshops ou conferencias. $E$ que, independentemente do tipo de consulta, informações necessárias devem ser apresentadas com antecedência, facilitando que os participantes respondam e participem de debates com trocas diretas entre os diferentes grupos.

Contudo, essa orientação precisa ser problematizada: a "troca direta" só pode ocorrer se todos os participantes envolvidos estiverem em igualdade de condições e com tempo suficiente para análises e debates. E aqui todos os "senões" em relação à informação para a tomada de decisão devem ser retomados. Matérias tão complexas e potencialmente conflituosas como regras para emissão de outorga ou cobrança pelo uso da água demandam muitos e diferentes tipos de encontros. Sob o risco de que as decisões sobre tais assuntos ocorram nos fóruns segmentados ou especializados, em negociações com atores de maior poder econômico e/ou político. Nesse caso, as consultas públicas serviriam apenas para referendar o que já fora previamente decidido.

Se a análise dos processos de planejamento de recursos hídricos indicou a tendência de crescimento das modalidades de consultas, ainda predominam as denominadas "reuniões públicas de consulta". Os documentos das bacias do São Francisco e das Velhas, por exemplo, descrevem a realização de 28 e 26 reuniões dessa modalidade, respectivamente - uma para cada Unidade Territorial Estratégica (UTE). Já as previsões de 10 eventos desse tipo na bacia rio Doce; e 11 no planejamento de Santa Maria e Jucu não foram cumpridas - basicamente por falta de público. Provavelmente devido às estratégias de divulgação equivocadas, conforme já comentado. De fato, ir além do público usual dos CBHs e órgãos gestores tem se constituído em grande desafio nos planejamentos estudados. Dentre os processos estudados, apenas os das bacias do São Francisco e das Velhas (bacia e bacia afluente, sob a gestão da mesma Agência de Bacias) superaram a expectativa de presenças.

Os relatórios sobre os eventos presenciais de consulta pública indicam o esforço de combinar métodos expositivos, interrogativos e avaliativos diretos e indiretos. Embora haja registros de envio preliminar do material, o usual é que as informações - ou pelo menos as questões centrais - fossem repassadas durante os encontros (em geral exposições feitas por especialistas, com apoio de audiovisuais). As consultas, nesse caso, correspondiam à manifestação dos presentes (geralmente por votação) ao final das palestras.

Em menor medida, além das reuniões públicas ou oficinas setoriais, foram identificadas outras modalidades de consulta. Alguns processos realizaram aplicação de questionários, entrevistas, reuniões com organizações chave. Em alguns casos, como nas bacias do São Francisco e das Velhas, especificamente na fase de Diagnóstico, foram utilizados vários instrumentos de consulta visando obter 
uma visão mais fiel dos diversos setores e da população sobre temas como usos preponderantes de recursos hídricos, fatores de pressão, tendências etc.

Dentre as inovações identificadas no quesito consultas, destacamos a análise de mídia, desenvolvida no processo da bacia São Francisco; e a consulta online articulada com os eventos presenciais, realizada na revisão do plano de plano do PCJ (2016-2017). No primeiro caso, foram analisados os temas "opinião pública e publicada sobre a bacia hidrográfica do São Francisco", em 2.495 publicações, no período de janeiro de 2012 a junho de 2015; e "movimentos sociais e manifestações públicas de opinião", em 150 publicações, de março de 2011 a junho de 2015. No caso do PCJ, após as reuniões presenciais, eram abertas consultas pela Internet visando aprofundamento do tema e ampliação do debate.

Outro ponto positivo identificado foi a tendência de realização de consultas dirigidas aos membros dos CBHs, técnicos e gestores antes do início do planejamento. Nesse caso, o objetivo é levantar sugestões para o Plano de Trabalho e, algumas vezes, para o Termo de Referência (TR) a ser firmado com a empresa consultora. Antecedendo ao processo de Enquadramento e Planejamento das bacias dos Rios Santa Maria da Vitória e Jucu, por exemplo, foram aplicados questionários a este grupo específico, com o objetivo de identificar atores e meios de comunicação estratégicos no território.

Nos termos da OIDP (2006), um dos critérios da qualidade democrática dos processos participativos está justamente na possibilidade de os participantes contribuírem com observações e propostas. Mas é essencial que os conteúdos dos distintos aportes sejam sistematizados e que se possa analisar sua evolução ao longo do debate e seus resultados nas decisões finais. Paradoxalmente, a despeito dos avanços, ainda há poucos investimentos ou atenção a esse tópico. De fato, a devolutiva e especificação de como ou quais contribuições foram aproveitadas não têm merecido atenção dos organizadores. Trata-se de uma deficiência que compromete os resultados e o próprio sentido das consultas (OCDE, 2002). Apenas nos planejamentos da bacia do São Francisco identificou-se a publicação de relatórios específicos sobre os resultados de cada um dos tipos de consultas realizadas e o aproveitamento das contribuições no Plano Final.

\subsection{Envolvimento ativo}

A rigor, a definição de envolvimento ativo na análise dos níveis de participação resulta mais difícil. Teóricos que discorrem sobre a questão concordam que essa é a última etapa de um longo processo. Busca-se, aqui, o empoderamento dos cidadãos em relação ao debate e deliberação sobre as políticas públicas. Segundo a OCDE (2002), trata-se da forma mais avançada de relação entre governo-cidadão, na qual os governos reconhecem e apoiam a participação dos cidadãos no estabeleci- 
mento da agenda da política no exercício de influência significativa na formulação de políticas públicassem que isso reduza as atribuições do governo. Por exclusão, podemos dizer que o envolvimento ativo não se limita ao recebimento de informações ou à colaboração via consultas, mas pretende a partilha do poder - o que não ocorre sem tensões.

Embora originalmente a DQA não detalhe as condições ou características desse nível de participação, documentos posteriores à Diretiva buscaram indicar caminhos para promover o envolvimento ativo: entrevistas, escuta ativa, workshops, sessões criativas, júri de cidadão, sistemas de informação geográfica interativa (Web SIG), audiências públicas, monitoramento/avaliações participativas, ferramentas informáticas para o processamento de comentários públicos (CCE, 2003). E aqui, encontramos, igualmente como na Resolução № 145/2012, uma confusão entre métodos/técnicas e a finalidade da participação neste nível. Entretanto, dois pontos merecem destaque na relação proposta pela OCDE: a sugestão do monitoramento/avaliações participativas e da implementação de ferramentas informáticas para o processamento de comentários públicos. Ambas as propostas guardam relação com uma participação consequente. E, não por casualidade, têm correspondência com os elementos que contribuem com a qualidade democrática dos processos participativos descritos pelo OIDP (2006).

Segundo a DQA, o envolvimento ativo tem como característica a seletividade, o que exige que seja representativo. Assumindo que a finalidade última da participação é a partilha de poder, strito sensu o envolvimento ativo no planejamento dos recursos hídricos está reservado aos CBHs já que, legalmente, cabe a eles a aprovação final do plano. Tal como os conselhos de politicas públicas, os comitiês de bacia "constituem desenhos institucionais de partilha do poder e são constituídos pelo próprio Estado, com representação mista de atores da sociedade civil e atores estatais" (AVRITIZER, 2008, p. 44). Segundo o mesmo autor, diferentemente dos outros tipos de IPs, arranjos como os conselhos de políticas públicas não incorporam um número amplo de atores sociais, porque são determinados por lei que estabelece a instauração do processo participativo, sob pena de sanções. Nesse sentido, as consultas são um complemento útil e podem funcionar como um tipo de controle no envolvimento ativo, para que todos os interesses, pontos de vista estejam representados (CCE, 2003, p. 36) [Tradução nossa].

No caso dos CBHs, sua composição prevê a representação dos vários seguimentos com interesse nos recursos hídricos da bacia. Mas, a aprovação final do PRHs - ainda que prerrogativa de um grupo reduzido - implica considerar as discussões e propostas oriundas do processo participativo e nesse sentido deve corresponder a um "pacto construído entre os atores envolvidos" (ANA,, 2013. p. 21). Assim, em alguma medida, também registra-se o envolvimento ativo dos vários atores que contribuem com informações e propostas para compor o diagnóstico e as propostas finais do plano, bem como em sua execução. Um exemplo nesse sentido é o do rio das Velhas que, posteriormente às 
reuniões públicas, promovia encontros com atores estratégicos da bacia (órgão gestor de recursos hídricos, AGB Peixe Vivo, representantes da sociedade civil, da indústria, mineração e agropecuária e empresas de saneamento, dentre outros) com objetivo de

[...] levantar posicionamentos que apontassem para as diretrizes gerais a serem propostas para os instrumentos de gestão de recursos hídricos e colher, na perspectiva dos principais atores estratégicos, avaliações sobre as limitações e oportunidades que se apresentam para a consecução destas diretrizes e para a composição de um arranjo institucional competente e apropriado para a implementação do PDRH Rio das Velhas (VELHAS, 2015, p.304).

\subsection{Entre as velhas e as novas tecnologias}

Atualmente, nenhum debate sobre a participação pública, independentemente do nível ou grau, pode desconsiderar o papel das NTIC e as mídias sociais. Fundamentalmente, elas ampliaram as possibilidades de acesso à informação, de transparência e de interação, potencializando a qualidade democrática de processos participativos. Não por acaso, a OCDE (2002) aponta que elas trazem novas oportunidades e ferramentas poderosas para o fortalecimento das relações governo-cidadão e recomenda seu uso integrado com as ferramentas tradicionais. Nesse sentido, é pertinente observar, ainda que rapidamente, se e como as NTIC foram integradas aos espaços e procedimentos participativos no planejamento de recursos hídricos.

A primeira constatação é que sua incorporação nos processos de elaboração de PRHs é uma tendência inequívoca. Se os documentos relativos ao PRH do Rio Doce sequer mencionam NTIC ou mídias sociais, nos casos mais recentes elas são referências constantes ${ }^{7}$. Em geral, elas foram usadas para transmitir informações e convites relativos ao planejamento, disponibilizar relatórios ou material de apoio e realizar consultas online. Nesse sentido, contribuem para resolver as dificuldades em relação à divulgação da proposta e dos eventos relacionados - tanto em termos de custos como de abrangência. Cartazes-convites ou relatórios dos eventos, por exemplo, passaram a ser disponibilizados pelas redes sociais, facilitando seu acesso. Facebook, WhatsApp, E-mails, dentre outras mídias/ferramentas tornaram-se fundamentais para garantir os fluxos internos e também externos de comunicação. Curiosamente, embora os CBHs (com exceção dos de Santa Maria da Vitória e do Jucu) tenham canais no YouTube e, em maior ou menor grau, produzam regularmente vídeos informativos e educativos, não foram identificadas produções relativas ao planejamento propriamente dito.

No universo das NTIC, os sítios eletrônicos têm merecido mais atenção e investimento por parte dos organizadores que passaram a criar portais ou páginas específicas para cada processo. Além de disponibilizar as informações oficiais das atividades relacionadas ao planejamento de recursos hídricos, os sítios eletrônicos funcionam como repositórios dos materiais produzidos, como atas, estudos e 
apresentações, e links de interesse. Em menor medida, oferecem ferramentas de interação para envio de mensagens, sugestões e até para a realização de consultas.

Em sintonia com a valorização das consultas públicas via Internet no Brasil, os processos mais recentes de elaboração dos PRHs passaram a incluir essa modalidade de participação. No caso das bacias do São Francisco e das Velhas, além de facilitar o contato com grupos ou atores estratégicos (especialmente por e-mails), as NTIC serviram para realização de consultas. Um arranjo interessante foi observado na revisão do Plano de bacias PCJ que articulou a participação presencial nos encontros com as consultas pela Internet - possibilitando aos presentes (e mesmo os ausentes) se manifestar, por exemplo, após a discussão com seus próprios grupos ou entidades. Ainda é cedo para analisar se a tendência é que as consultas via Internet sejam usadas para complementar ou para substituir as presenciais (como as reuniões públicas ou workshops). Inegavelmente, essa modalidade de consultas pode incorporar novos atores ao debate do planejamento e há uma série de arranjos a serem experimentados nesse sentido.

Entretanto, ainda que as NTIC e as mídias sociais já sejam parte das rotinas dos planejamentos de recursos hídricos, fundamentalmente não encontramos estratégias diferenciadas ou inovadoras em relação ao seu uso no sentido de ampliar ou qualificar a participação. Elas têm sido usadas prioritariamente para "informar" (sobre os eventos, resultados dos processos - geralmente em forma de relatórios), em detrimento de suas possibilidades de interação. E, como informar, leia-se "documentos em formatos de impressos", ainda que veiculados por mídia eletrônica. Pouca ou nenhuma atenção tem sido dada a outros tipos de linguagem, como audiovisual, que poderiam fortalecer a Mobilização e, ainda, a qualificação dos atores envolvidos direta ou indiretamente no planejamento. Confirma-se, dessa forma, a observação de Subirats (2011): no campo da política, os partidos e instituições que passaram a usar as NTIC o fazem na velha lógica, a do "velho martelo de sempre". Ou seja, o controle do meio e a decisão sobre o formato e limites da troca de informação ou opiniões continuam sendo da coordenação do partido ou da instituição. Nesse aspecto, as NTIC mantêm os fluxos de unidirecionais de sempre. Noutros termos, não concorrem para ampliar a qualidade democrática dos processos de elaboração de planos de bacia.

\section{REFLEXÕES FINAIS}

A análise das IPs criadas após a Constituição brasileira de 1988 mostra que as estruturas e mecanismos para que cidadãos se envolvam na formulação, implementação e avaliação das políticas públicas ainda não desenvolveram plenamente ou são isentas de contradições. Verifica-se, inclusive, certo esvaziamento ou banalização do "participativo" no âmbito dos conselhos de políticas públicas ou 
comitês de bacia, apontado por autores como Dagnino (2014), Santos e Saito (2006) e Machado (2003). Nas palavras de Tatagiba (2003, p. 13), "não são raros os casos em que gestores públicos e comunidades pensam o novo e realizam o velho, apegados que estão ou impossibilitados que são de renovarem o pensamento e a prática política". Nessa lógica, questiona-se em que medida a dinâmica desses espaços permite ou não práticas progressistas e inovadoras de participação.

Tendo como meta a qualidade democrática dos processos participativos (OIDP, 2006), a análise de "como se participa" no planejamento de recursos hídricos apontou a necessidade de ir além da discussão sobre métodos e técnicas - mas avançar sobre o real envolvimento ou empoderamento dos atores que aderem a esses processos que, por força de lei, devem ser participativos. Análises sobre a participação na gestão dos recursos hídricos em geral, coincidem que, se ao lado do crescimento quantitativo, persistem problemas relacionados à qualidade da participação. Dentre as razões está a falta de capacitação, técnica ou política, de grande parte dos usuários, para atuar efetivamente nos vários fóruns. Além disso, nem todos os grupos de usuários estão organizados e têm articulações para atuação de forma mais incisiva nos fóruns de debate.

O exame dos documentos relativos à elaboração dos PRHs das bacias do Doce; Piracicaba, Capivari e Jundiaí (PCJ); Santa Maria e Jucu; São Francisco, e rio das Velhas confirmaram a falta de clareza na designação, descrição e mesmo intenção dos denominados espaços e procedimentos participativos. Se o objetivo for apenas atender às orientações internacionais e diretrizes legais, a participação termina reduzida aos procedimentos instrumentais. Fazendo um paralelo com a análise de Tatagiba (2003, p. 15) sobre os modelos de gestão e cultura política local: "a participação pode não ser pública, nem tampouco democrática". Corre o risco de ser entendida de diferentes formas e servir a diferentes propósitos.

Nesse sentido, importa clarificar os objetivos e alcances de cada nível de participação. Inclusive para tornar mais precisas as análises sobre "como se participa" no planejamento de recursos hídricos e propor 0 aperfeiçoamento desses processos em relação a sua qualidade democrática. Nessa perspectiva, buscamos rever e atualizar a discussão dos níveis ou graus de participação púbica. $\mathrm{E}$ a sua aplicação (ainda que parcial) por organismos como a OCDE (2002) e, especialmente a CCE (2000, 2003) em suas orientações sobre a gestão dos recursos hídricos. Se a participação pública é um processo com diferentes níveis de envolvimento e empoderamento, seu fim último é partilha de poder conforme preconiza a Constituição de 1988, a PNRH (BRASIL, 1997; ANA, 2013) e assumem vários autores (AVRITZER, 2008; DAGNINO, 2014). Essa perspectiva de análise permite-nos avançar além dos procedimentos técnico-metodológicos para verificar em que medida os $\mathrm{PRH}$ têm se constituído, de fato, em uma construção coletiva visando os usos múltiplos da água e resguardando o recurso para as gerações presentes e futuras (ANA, 2011). Ainda que a premissa deste trabalho seja a defesa da 
qualidade democrática da participação pública no planejamento de recursos hídricos, é honesto assumir que:

Nenhum modelo de governança é um fim em si mesmo. Portanto, se é bom ou ruim não o é por razões teóricas ou conceituais. Ele é bom se resolve efetiva e adequadamente as questões chave de recursos hídricos, em conformidade com os princípios globais, tais como eficiência, responsabilidade, justiça, legitimidade e total conformidade com a lei (OCDE, 2015, p. 90).

Tratando dos níveis de participação, o primeiro deles é o da Informação. Metodologicamente, a diferenciação entre Informação para tomada de decisão e Informação para Mobilização permitiu-nos maior assertividade no exame da concepção e práticas de comunicação dos planejamentos em estudo. Sobre o primeiro item, em síntese, os processos com maior qualidade democrática são aqueles nos quais os participantes recebem toda a informação necessária para deliberar em condições de igualdade e tomar uma decisão de forma democrática (OIDP, 2006). Não obstante, ainda há um longo caminho para a efetivação do "direito à informação". O esforço nos processos analisados é mais no sentido de cumprir uma formalidade, desconsiderando a função orientadora e articuladora dos materiais produzidos. Há poucos investimentos/avanços em relação a suportes, formatos e linguagens e 0 resultado é uma documentação pouco acessível, basicamente técnica, o que reforça assimetrias e poderes estabelecidos. Também não se identificou esforços para "traduzir" aos técnicos e consultores as experiências, propostas e valores dos seguimentos mais vulneráveis e não habituados aos procedimentos e linguagens de fóruns desse tipo. Contudo, são necessárias avaliações mais detalhadas sobre os conteúdos para subsidiar consultas e tomadas de decisão nos processos de planejamento de recursos hídricos e, também, de sua recepção. Chamamos a atenção, ainda, para a questão do tempo de duração dos processos de planejamento. A necessidade de cumprir prazos contratuais cria o que Espluga e Subirats (2008) denominaram de "dinâmica de urgência". O que significa períodos curtos para assimilação e debate das informações.

Sobre a Informação para a mobilização, é revelador que os planos de mídia (ou o que mais se assemelhava a eles) sejam distintos do plano de mobilização. Em síntese, a comunicação não tem sido compreendida em sua complexidade, em perspectiva relacional e como elemento constitutivo do próprio processo de mobilização. Ou seja, a concepção de comunicação das organizações do Estado segue centrada no uso dos meios massivos para fortalecer / promover a imagem institucional (LÓPEZ, 2004). E não como conceito e ferramenta para a construção democrática da sociedade e planejamento estratégico das organizações ou processos públicos.

Em relação às consultas, observa-se um avanço em termos de quantidade e variedade, inclusive a tendência de incorporação das NTIC. Contudo, várias questões permanecem em aberto. Nem sempre está claro se (todas) as consultas realizadas durante as reuniões públicas foram precedi- 
das de ampla divulgação, inclusive sobre os procedimentos e as temáticas (com informações prévias). Também é preciso avançar em termos de publicização dos resultados das consultas e a sua contribuição para o planejamento parecem ser comuns.

Já em relação ao Envolvimento ativo, último ou maior nível de participação, embora seu significado seja aparentemente claro - partilha de poder - a descrição dos espaços e métodos para sua consumação resultou mais difícil. Em geral, os documentos que reduzem a questão a procedimentos metodológicos (CCE 2003; OCDE 2002) quando se trata de algo mais complexo. Estritamente nos termos legais, os CBHs são as IPs onde ocorre, de fato, a partilha do poder - já que dentre suas atribuições está a aprovação do plano de recursos hídricos. Mas, se consideramos que o PRH aprovado resultada de um processo anterior que envolveu outros atores para além do comitê, em tese partilha-se a partilha de poder.

É fato que os espaços/procedimentos de deliberação e os de consulta guardam maior potencial pedagógico e político (em relação à partilha de poder) do que aqueles meramente informativos. Contudo, é preciso evitar a associação direta entre maior grau de participação e maior qualidade democrática, Se por um lado, maior o grau de participação corresponde também à ampliação dos direitos e responsabilidades cidadãs, há outros elementos a se considerar: "Certos processos deliberativos podem ter uma grande qualidade e um enorme potencial pedagógico enquanto outros processos unicamente de decisão podem ser de baixa qualidade em função de quem sejam os participantes e que restrições haja em relação à tomada de decisões (ESPLUGA; SUBIRATS, 2008, p. 2, tradução nossa).

Em relação aos procedimentos metodológicos em geral, chama atenção a falta de inovação ou criatividade: predominam as reuniões ou workshops, dirigidos por gestores ou técnicos, com apoio de impressos, dinâmicas de grupos e votações nos formatos tradicionais. Os canais e formatos de informação utilizados são bastante convencionais, apesar da grande experiência no Brasil em Comunicação Alternativa8.

Stricto sensu, o processo de planejamento em si, com os vários atores e segmentos (re)conhecendo e discutindo alternativas para a bacia hidrográfica é educativo. Porém, apesar da recomendação expressa da Resolução CNRH No 145/2012, não foram identificados relatos de ações de Educação Ambiental nos casos em estudo. Contudo, práticas nessa linha, com suas possibilidades de articular sensibilidades e sustentabilidades (ALMEIDA, 2013), são desenvolvidas rotineiramente, por exemplo, pelo CBH do rio São Francisco (PAULA JUNIOR; MODAELLI, 2013). Nessa mesma linha estão as Descidas Ecológicas do rio Jucu, promovidas por organizações ambientais com apoio de gestores locais. A $16^{a}$ edição do evento, em 2005, discutiu a gestão dos recursos hídricos e culminou com a instalação do CBH Jucu. Já em 2013, a $24^{\circ}$ edição da Descida do rio Jucu reivindicou a criação de uma agência das águas, cuja responsabilidade seria coordenar a gestão compartilhada e integrada dos 
recursos hídricos estaduais ${ }^{9}$. Porém, não há registros de Descidas do rio Jucu tratando da temática planejamento de recursos hídricos.

Em resumo, nos processos participativos de planejamento de recursos hídricos observase pouca ou nenhuma ousadia de sair do conforto das salas de oficinas e reuniões (e de suas formalidades e linguagens estabelecidas) e buscar alternativas inovadoras para promover melhor compreensão acerca dos mundos naturais, das paisagens humanas, dos arredores físicos e biológicos (ALMElDA, 2013). Nem mesmo as NTIC foram exploradas nesse sentido. Nesse cenário há pouca margem para emergência e debate dos conflitos ou construção de uma percepção social sobre a água em suas múltiplas dimensões.

É compreensível, pois, há dificuldade dos organizadores para atrair um público mais amplo além daqueles atores que usualmente giram em torno dos comitês ${ }^{10}$. Não é por outra razão que Avritzer e Costa (2004) sugerem uma nova uma concepção discursiva de espaço público na América Latina que considere públicos novos ou emergentes e se mostre poroso não apenas à força expressiva dos argumentos racionais, mas também às formas não verbais de comunicação, pois,

[...] na medida em que a política contemporânea se rege pelo império da palavra, pela imposição da separação entre ética e estética, performance e racionalidade, decide-se previamente o jogo político em contra àqueles que, por força de sua inserção na história moderna, não puderam assumir o controle dos mecanismos de produção e reprodução dos discursos de poder considerados legítimos em cada Estado-nação particular (AVRITZER; COSTA, 2004, p. 712).

Explorar outras possibilidades além do espaço/formato tradicional da esfera pública pode fortalecer não apenas os compromissos formais em relação ao PRH em si, mas o compartilhamento de visões de mundo em torno de uma utopia: a bacia que queremos. Falta "democratizar a democracia" (SANTOS, 2002) e assumir conceitual e operacionalmente que vivemos noutro tipo de sociedade, marcada por expressões individualizadas e relações horizontais, o que exige outra forma de fazer política (SUBIRATS, 2011). Enfim, não há mais espaços para organizações ou processos hierarquizados, aos quais os cidadãos são convidados a "participar" segundo fórmulas pré-estabelecidas. Sem garantias de que possam modificar os fluxos unidirecionais de informação. E sem clareza de que suas contribuições serão consideradas.

Finalmente, considerando que, além de maior protagonismo dos cidadãos (em termos quantitativos e qualitativos), ampliar a qualidade democrática dos PRHs significa potencializar a solução dos problemas reais, chama a atenção o pouco apreço à documentação e registro dos processos examinados. A inexistência de uma prática de registro permanente e sistematizado do que é suscetível a converter-se em informação é considerada por Lópes (2004) um dos riscos à comunicação democrática do Estado. De maneira geral, a documentação não é tida como parte essencial da construção do 
público, fundamental para compreender os processos participativos nessa relação governo-sociedade e facilitar as ações para seu aprimoramento. Mesmo quando há registros do processo e de seus produtos, nem sempre está garantida a publicização, especialmente em longo prazo, o que facilitaria o monitoramento do plano e, logo, dos órgãos gestores. Não por acaso os esforços dos organizadores centram-se nos eventos/consultas e enquanto mecanismos de participação continuada para monitoramento da implementação dos planos e demais instrumentos de gestão sequer são discutidos.

\section{REFERENCIAS}

ALMEIDA, Denize Mezadre de. Educação ambiental nas travessias, aventuras e paixões das experiências-sentidos de professores/as com o local. Dissertação (Mestrado em Educação) - Universidade Federal do Espírito Santo, Centro de Educação, 2013.

AGÊNCIA NACIONAL DE ÁGUAS (Brasil). 0 Comitê de Bacia Hidrográfica: o que é e o que faz? Brasília (DF): SAG, 2011.

AGÊNCIA NACIONAL DE ÁGUAS (Brasil). Planos de recursos hídricos e enquadramento dos corpos de água. Brasília (DF), 2013.

AGÊNCIA NACIONAL DE ÁGUAS (Brasil). Conjuntura dos recursos hídricos no Brasil 2017: relatório pleno. Brasília (DF), 2017.

ARNSTEIN, Sherry Phyllis. Uma escada da participação cidadã. Participe - Revista da Associação Brasileira para a Promoção da Participação, Porto Alegre, n. 2, ano 2, p. 4-13, jan. 2002.

AVRITZER, Leonardo; COSTA, Sérgio. Teoria crítica, democracia e a esfera pública: conceitos e usos na América Latina. DADOS - Revista de Ciências Sociais, Rio de Janeiro, v. 47, n. 4, p.703-728, 2004. Disponível em: https://www.scielo.br/pdf/dados/v47n4/a03v47n4.pdf. Acesso em: 11 nov. 2018.

AVRITZER, Leonardo. A qualidade da democracia e a questão da efetividade da participação: mapeando o debate, in: PIRES, R. R.C. (org.) Efetividade das instituições participativas no Brasil: estratégias de avaliação. Brasília: Ipea, 2011. v. 7. p. 13-25.

AVRITZER, Leonardo. Instituições participativas e desenho institucional: algumas considerações sobre a variação da participação no Brasil democrático. Opinião Pública, Campinas, v.14 n.1, p.43-64, jun. 2008. Disponível em: https://www.scielo.br/pdf/op/v14n1/02.pdf. Acesso em 02 abr.2018.

BORDENAVE, Juan Enrique Díaz. O que é participação. São Paulo: Brasiliense, 1994.

BRASIL. Presidência da República. Lei no 6.938 de 31 de agosto de 1981. Política Nacional do Meio Ambiente. Diário Oficial [da] República Federativa do Brasil, Brasília (DF), 02 set.1981.

BRASIL. Presidência da República. Lei nº 9.433, de 8 de janeiro de 1997. Política Nacional de Recursos Hídricos, Sistema Nacional de Gerenciamento de Recursos Hídricos. Diário Oficial [da] República Federativa do Brasil, Brasília (DF), 08 jan. 1997. 
BRASIL, Presidência da República. Lei no 10.650, de 16 de abril de 2003. Diário Oficial [da] República Federativa do Brasil, Brasília (DF), 17 abr. 2003.

BRASIL, Presidência da República. Lei no 12.527, de 18 de novembro de 2011. Diário Oficial [da] República Federativa do Brasil, Brasília (DF), 28 nov.2011.

BRASIL, Presidência da República. Resolução n¹45, de 12 de dezembro de 2012. Estabelece diretrizes para a elaboração de Planos de Recursos Hídricos de Bacias Hidrográficas e dá outras providências. Diário Oficial [da] República Federativa do Brasil, Brasília (DF), 26 fev. 2013.

BRASIL, Presidência da República. Consultas Públicas. Disponível em: http://www.brasil.gov.br/consultas-publicas. Acesso em 28 mai. 2018.

BUARQUE, Sérgio José Cavalcante. Metodologia de planejamento do desenvolvimento local e municipal sustentável - Material para orientação técnica e treinamento de multiplicadores e técnicos em planejamento local e municipal. Gabinete do Ministro Extraordinário da Política Fundiária - MEPF/ Instituto Nacional de Colonização e Reforma Agrária - INCRA Instituto Interamericano de Cooperação para a Agricultura - IICA: Brasília, 1999.

COMISSÃO DAS COMUNIDADES EUROPÉIAS. Convenção sobre acesso à informação, participação do público no processo de tomada de decisão e acesso à justiça em matéria de ambiente. Dinamarca, 1998. Disponível em: http://eur-lex.europa.eul. Acesso em: 14 set. 2017.

. Directiva 2000/60/CE do parlamento europeu e do conselho. Jornal Oficial das Comunidades Europeias, Portugal, I 327/1, 2000. Disponível em: https://www.apambiente.pt. Acesso em: 14 set. 2017.

Public Participation in relation to the Water Framework Directive (Common Implementation Strategy for the Water Framework Directive [2000/60/EC] Guidance Document n. 8). Oficina de Publicaciones Oficiales de las Comunidades Europeas, Luxemburgo, 2003. Disponível em:

http://eur-lex.europa.eu/. Acesso em: 14 set. 2017.

CONFERÊNCIA INTERNACIONAL DE ÁGUA E MEIO AMBIENTE. Princípios de Dublin, 1992 (ICWE). Disponível em: http://www.agda.ptl. Acesso em 14 set. 2017.

CONFERÊNCIA DAS NAÇÕES UNIDAS SOBRE MEIO AMBIENTE E DESENVOLVIMENTO. Agenda 21 Global. Rio de Janeiro: Centro de Informações das Nações Unidas, 1992.

DAGNINO, Evelina. Estado Ampliado: Para Além da Democracia Representativa, in Seminário Democracia e Participação Cidadã, Curitiba, 2014. Disponível em:

https://www.youtube.com/watch?v=39cEQ3nzBWI\&t=1327s. Acesso em 5 abr. 2018.

EMPINOTTI, Vanessa Lucena; JACOBI, Pedro Roberto; FRACALANZA, Ana Paula. Transparência e a governança das águas. Estudos Avançados, São Paulo v. 30, n. 88, p. 63-75. 2016.

ESCOREL, Sarah. Reconhecer e superar os limites da participação institucionalizada. Cad. Saúde

Pública, Rio de Janeiro, v. 31, n. 10, p. 2047-2072, out. 2015. Disponível em:

https://www.scielo.br/pdf/csp/v31n10/0102-311X-csp-31-10-2059.pdf. Acesso em 22 abr.2018. 
ESPLUGA, Josep; SUBIRATS, Joan. Participación ciudadana en las políticas de agua en España. Fundación Nueva Cultura del Agua - Painel Científico-Técnico de Seguimiento de la Política de Aguas. Convenio Universidad de Sevilla-Ministerio de Medio Ambiente, 2008.

HENRIQUES, Márcio Simeone (org). Comunicação e Estratégias de Mobilização Social. 3. ed. Belo Horizonte: Autêntica, 2013.

INSTITUTO DE PESQUISA ECONÔMICA APLICADA. Instituições Participativas e Políticas Públicas no Brasil: características e evolução nas últimas duas décadas. Brasília: IPEA, 2010.

0 Conselho Nacional de Recursos Hídricos na Visão de seus Conselheiros. Relatório de Pesquisa Projeto Conselhos Nacionais: perfil e atuação dos conselheiros. Brasília: IPEA, 2012.

LIMA, Angelo José Rodrigues. Governança dos recursos hídricos: proposta de indicador para acompanhar sua implementação. São Paulo: WWF - Brasil: FGV, 2014.

LÓPEZ, Juan Camilo Jaramillo. Modelo de comunicación pública organizacional e informativa para entidades del Estado. Bogotá (Colômbia): Usaid - Casals \& Associates, 2004.

MACHADO, Carlos José Saldanha. O mundo da administração pública das águas do estado do Rio de Janeiro segundo o olhar de um antropólogo. Horizontes Antropológicos, Porto Alegre, n. 25, ano 12, p. 171-190, jan./jun. 2006.

Recursos Hídricos e Cidadania no Brasil: Limites, Alternativas e Desafios. Ambiente \& Sociedade, VI, n. 2, p. 121-136, jul./dez. 2003.

MAFRA, Rennan. Entre o espetáculo, a festa e a argumentação: mídia, comunicação estratégica e mobilização social. Belo Horizonte: Autêntica, 2006.

MEDINA, Cremilda Celeste de Araújo. Símbolos e narrativas: rodízio 97 na cobertura jornalística. São Paulo: Secretaria do Meio Ambiente, 1998.

ORGANIZAÇÃO PARA A COOPERAÇÃO E O DESENVOLVIMENTO ECONÔMICO. Governança dos Recursos Hídricos no Brasil, OECD Publishing, Paris, 2015. Disponível em: www.oecdilibrary.org. Acesso em 19 set. 2017.

0 cidadão como parceiro. Manual da OCDE sobre informação, consulta e participação na formulação de políticas públicas. Brasilia: MP, SEGES, 2002.

OBSERVATÓRIO INTERNACIONAL DE DEMOCRACIA PARTICIPATIVA. Guía Práctica para la evaluación de procesos participativos. OIPD: Barcelona. 2006.

PAULA JUNIOR Franklin e MODAELLI, Suraya (orgs). Política de águas e educação ambiental: processos dialógicos e formativos em planejamento e gestão de recursos hídricos. 3.ed., rev. e ampl.; Brasilia: MMA/SRHU, 2013.

PERUZZO, Cicilia Maria. Krohling. Conceitos de comunicação popular, alternativa e comunitária revisitados. Reelaborações no setor. Palabra Clave, [S.I.], v. 11, n. 2, jul. 2009. Disponível em: https://palabraclave.unisabana.edu.co/index.php/palabraclave/article/view/1503/1744. Acesso: 10 fev. 2019. 
PIRES, Roberto Rocha Coelho et al. Em busca de uma síntese: ambições comuns e abordagens diversificadas na avaliação da efetividade das instituições participativa. in: PIRES, Roberto Rocha Coelho. (org). Efetividade das instituições participativas no Brasil: estratégias de avaliação. Brasília: Ipea, v. 7 p. 347-362, 2011.

PLANO DE RECURSOS HÍDRICOS DA BACIA HIDROGRÁFICA DO RIO SÃO FRANCISCO 20162025. RT1B. Diagnóstico da dimensão da participação social. Bahia: NEMUS, 2015.

PLANO DIRETOR DE RECURSOS HÍDRICOS DA BACIA HIDROGRÁFICA DO RIO DAS VELHAS. Prognóstico e plano de ações. Belo Horizonte, 2015.

PLANO DAS BACIAS HIDROGRÁFICAS DOS RIOS PIRACICABA, CAPIVARI E JUNDIAÍ 2010 A 2020. Relatório final. São Paulo, 2010.

RABELO, Desirée Cipriano. Comunicação e Mobilização na Agenda 21 local. Vitória: EDUFES/Facitec, 2003.

SANTOS, Boaventura de Sousa (org). Democratizar a democracia: os caminhos da democracia participativa. Rio de Janeiro: Civilização Brasileira, 2002.

SANTOS, Irenilda Angela dos; SAITO, Carlos Hiroo. A mitificação da participação social na política nacional de recursos hídricos - gênese, motivação e inclusão social, Geosul, Florianópolis, v.21, n. $42,2006$.

SUBIRATS, Joan. Otra sociedad ¿Otra política? De «no nos representan» a la democracia de lo común. Barcelona: Icaria Editorial, 2011.

TATAGIBA, Luciana. Participação, cultura política e modelos de gestão: a democracia gerencial e suas ambivalências. (Tese) Doutorado em Ciências Sociais - Unicamp. Campinas, 2003.

TORO, Jose Bernardo; WERNECK, Nísia Maria Duarte. Mobilização Social: Um modo de construir a democracia e a participação. Belo Horizonte: Autêntica, 2004.

\section{Notas}

10 termo Instituições Participativas é assumido aqui no sentido atribuído por Avritzer (2008): formas diferenciadas de incorporação de cidadãos e associações da sociedade civil na deliberação sobre políticas. A classificação considera três variáveis: iniciativa na proposição do desenho, organização da sociedade civil na área em questão e vontade política do governo em implementar a participação (AVRITIZER, 2008, p. 46).

2 Dentre os inúmeros estudiosos que se dedicam ao tema, destacamos aqui Jacobi (2007, 2009 2017), Santos e Saito (2006) e Machado $(2003,2016)$. Numa perspectiva mais técnica, temos a Agência Nacional de Águas, especialmente com os relatórios de conjuntura publicados anualmente; e as organizações internacionais, como Organização para a Cooperação e o Desenvolvimento Econômico (OCDE, 2015) e a Word Wildlife Fund Brasil (LIMA, 2014).

${ }^{3}$ As informações aqui apresentadas têm como fonte principal os sítios dos próprios $\mathrm{CBH}$ e os dados apresentados nos Diagnósticos dos Planos em estudo.

4 Tendo em conta as especificidades dos PRHs (que em última instância são aprovados pelos CBHs), eles podem ser considerados uma IP híbrida, com características do modelo descrito por Avritzer (2008, pág. 46): aquele "no qual ocorre 
um processo de ratificação pública, ou seja, no qual se estabelece um processo em que os atores da sociedade civil não participam do processo decisório, mas são chamados a referendá-lo publicamente".

5 A comunicação macro (com ou sem instrumentos de intermediação) é aquela voltada a seguimentos específicos, recorrendo às linguagens e argumentos próprios desses seguimentos, buscando informar, consultar e/ou promover a adesão dos diferentes grupos.

${ }^{6}$ Embora esse tipo de informação seja essencial, outros tipos de (in)formações também são necessárias para a qualidade dos processos participativos em debate. Faltam, por exemplo, ações de capacitação e conscientização sobre o papel do cidadão nos espaços de participação na política dos recursos hídricos e sobre o próprio SINGREH, ainda desconhecido entre a população (LIMA, 2014).

7 Trata-se de uma lacuna compreensível. Aprovado em 2010, o processo do rio Doce é o mais antigo entre os pesquisados e um dos pioneiros no Brasil. Se ainda não eram comuns o uso das NTIC naquele momento, em sua época o PIRH do Doce inovou pela presença ativa dos comitês dos afluentes em todas as fases do plano (inclusive na elaboração do Termo de Referência) e, ainda na produção dos Planos de Ações para as Unidades de Gestão de Recursos Hídricos (PARHs). Atualmente o $\mathrm{CBH}$ Doce e a Agência fazem uso das redes sociais com frequência como o Facebook e mantém um sítio eletrônico bem atualizado, com acesso a vários links que tratam da temática de recursos hídricos e participação.

8 O "alternativo" aqui remete a outros suportes e linguagens que podem ampliar o debate dos temas em pauta. Noutros termos, possibilitar uma comunicação mais dialogal e crítica, facilitando a aproximação, sensibilização, envolvimento e protagonismos de setores habitualmente distantes de debates técnicos (KROHLING PERUZZO, 2009).

${ }^{9}$ A Agência Estadual de Recursos Hídricos (AGERH) foi criada nesse ano pela Lei 10.143, de 16/12/2013.

10 Para agravar, nessa representação particular da esfera pública, ainda assim persistem outras distorções em termos de representatividade: pesquisa realizada pelo IPEA (2012) sobre o perfil e atuação dos membros do Conselho Nacional de Recursos Hídricos apontou que a presença masculina é $70 \%$ maior que a feminina. Isso quando as organizações internacionais reconhecem o papel da mulher e a necessidade de incorpora-la no debate e gestão dos recursos hídricos. 